\section{Sotatercept, a novel transforming growth factor $\beta$ ligand trap, improves anemia in $\beta$-thalassemia: a phase II, open-label, dose-finding study}

Maria Domenica Cappellini, ${ }^{1}$ John Porter, ${ }^{2}$ Raffaella Origa, ${ }^{3}$ Gian Luca Forni, ${ }^{4}$ Ersi Voskaridou, ${ }^{5}$ Frédéric Galactéros, ${ }^{6}$ Ali T. Taher, ${ }^{7}$ Jean-Benoît Arlet, ${ }^{8,9,10}$ JeanAntoine Ribeil, ${ }^{11}$ Maciej Garbowski, ${ }^{2}$ Giovanna Graziadei, ${ }^{1}$ Chantal Brouzes, ${ }^{11}$ Michaela Semeraro, ${ }^{11}$ Abderrahmane Laadem, ${ }^{12}$ Dimana Miteva, ${ }^{13}$ Jun Zou, ${ }^{12}$ Victoria Sung, ${ }^{14}$ Tatiana Zinger, ${ }^{13}$ Kenneth M. Attie ${ }^{15}$ and Olivier Hermine ${ }^{9,10,16}$

${ }^{1}$ Fondazione IRCCS Ca' Granda Ospedale Maggiore Policlinico, Department of Clinical Sciences and Community Health, University of Milan, Italy; '2Department of Haematology, University College London, UK; ${ }^{3}$ Day Hospital Talassemia, Ospedale Pediatrico Microcitemico “A.Cao", A.O. "G. Brotzu”, Cagliari, Italy; ${ }^{4}$ Centro della Microcitemia, Ospedali Galliera, Genova, Italy; ${ }^{5}$ Thalassemia Center, Laikon General Hospital, Athens, Greece; 'UMGGR, Hôpital Henri Mondor; Assistance Publique-Hôpitaux de Paris (APHP); UPEC, Créteil, France; ' Department of Internal Medicine, American University of Beirut Medical

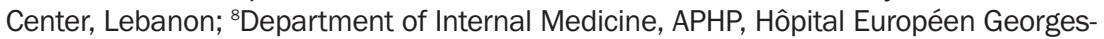
Pompidou, Paris, France; 'INSERM UMR1163, CNRS ERL 8254, Institut Imagine, Université Paris Descartes-Sorbonne Paris Cité, France: ${ }^{10}$ Laboratory of Excellence GR-Ex, Paris, France; ${ }^{11}$ Laboratory of Onco-hematology, Hôpital Necker-Enfants Malades, Paris, France; ${ }^{12}$ Celgene Corporation, Summit, NJ, USA; ${ }^{13}$ Celgene Corporation, Boudry, Switzerland; ${ }^{14}$ Celgene Corporation, San Francisco, CA, USA; ${ }^{15}$ Acceleron Pharma, Cambridge, MA, USA and ${ }^{16}$ Department of Hematology, APHP, Hôpital Necker, Paris, France

\section{ABSTRACT}

$\beta$ -thalassemia, a hereditary blood disorder caused by defective synthesis of hemoglobin $\beta$ globin chains, leads to ineffective erythropoiesis and chronic anemia that may require blood transfusions. Sotatercept (ACE-011) acts as a ligand trap to inhibit negative regulators of late-stage erythropoiesis in the transforming growth factor $\beta$ superfamily, correcting ineffective erythropoiesis. In this phase II, open-label, dose-finding study, 16 patients with transfusion-dependent $\beta$-thalassemia and 30 patients with non-transfusion-dependent $\beta$-thalassemia were enrolled at seven centers in four countries between November 2012 and November 2014. Patients were treated with sotatercept at doses of $0.1,0.3,0.5,0.75$, or $1.0 \mathrm{mg} / \mathrm{kg}$ to determine a safe and effective dose. Doses were administered by subcutaneous injection every 3 weeks. Patients were treated for $\leq 22$ months. Response was assessed as a $\geq 20 \%$ reduction in transfusion burden sustained for 24 weeks in transfusion-dependent $\beta$-thalassemia patients, and an increase in hemoglobin level of $\geq 1.0 \mathrm{~g} / \mathrm{dL}$ sustained for 12 weeks in non-transfusiondependent $\beta$-thalassemia patients. Sotatercept was well tolerated. After a median treatment duration of 14.4 months (range 0.6-35.9), no severe lifethreatening adverse events were observed. Thirteen percent of patients reported serious but manageable adverse events. The active dose of sotatercept was $\geq 0.3 \mathrm{mg} / \mathrm{kg}$ for patients with non-transfusion-dependent $\beta$-thalassemia and $\geq 0.5 \mathrm{mg} / \mathrm{kg}$ for those with transfusion-dependent $\beta$-thalassemia. Of 30 non-transfusion-dependent $\beta$-thalassemia patients treated with $\geq 0.1 \mathrm{mg} / \mathrm{kg}$ sotatercept, $18(60 \%)$ achieved a mean hemoglobin increase $\geq 1.0 \mathrm{~g} / \mathrm{dL}$, and $11(37 \%)$ an increase $\geq 1.5 \mathrm{~g} / \mathrm{dL}$, sustained for $\geq 12$ weeks. Four $(100 \%)$ transfusion-dependent $\beta$-thalassemia patients treated with $1.0 \mathrm{mg} / \mathrm{kg}$ sotatercept achieved a transfusion-burden reduction of $\geq 20 \%$. Sotatercept was effective and well tolerated in patients with $\beta$-thalassemia. Most patients with non-transfusion-dependent $\beta$-thalassemia treated with higher doses achieved sustained increases in hemoglobin level. Transfusion-dependent $\beta$-thalassemia patients treated with higher doses of sotatercept achieved notable reductions in transfusion requirements. This trial was registered at ClinicalTrials.gov with the number NCT01571635.
Haematologica 2019

Volume 104(3):477-484

\section{Correspondence:}

MARIA DOMENICA CAPPELLINI

maria.cappellini@unimi.it

OLIVIER HERMINE

olivier.hermine@nck.aphp.fr

Received: May 30, 2018.

Accepted: October 12, 2018.

Pre-published: October 18, 2018.

doi:10.3324/haematol.2018.198887

Check the online version for the most updated information on this article, online supplements, and information on authorship \& disclosures: www.haematologica.org/content/104/3/477

(C)2019 Ferrata Storti Foundation

Material published in Haematologica is covered by copyright. All rights are reserved to the Ferrata Storti Foundation. Use of published material is allowed under the following terms and conditions:

https://creativecommons.org/licenses/by-nc/4.0/legalcode. Copies of published material are allowed for personal or internal use. Sharing published material for non-commercial purposes is subject to the following conditions:

https://creativecommons.org/licenses/by-nc/4.0/legalcode, sect. 3. Reproducing and sharing published material for commercial purposes is not allowed without permission in writing from the publisher. 


\section{Introduction}

$\beta$-thalassemia is a hereditary blood disorder caused by defective synthesis of the $\beta$ globin chains of hemoglobin ${ }^{1}$ characterized by ineffective erythropoiesis. ${ }^{2.4}$ Mutations in the $\beta$-globin genes lead to reduced or absent $\beta$-globin chain synthesis, increasing the ratio of $\alpha$-globin to non- $\alpha$ globin chains. Due to the relative excess of $\alpha$-globin chains, $\alpha$-globin precipitates within erythroblasts as hemichromes, leading to oxidative stress, maturation arrest, membrane damage and apoptosis of late-stage erythroid precursors, and reduced red blood cell (RBC) life span. ${ }^{4.6}$ Although erythropoiesis-stimulating agents have been used in patients with $\beta$-thalassemia, ineffective erythropoiesis is not corrected.? Use of erythropoiesis-stimulating agents is, therefore, not recommended for the treatment of $\beta$-thalassemia. ${ }^{7,8}$

$\beta$-thalassemia phenotypes vary in severity, ranging from asymptomatic thalassemia minor to non-transfusiondependent thalassemia (NTDT) (including thalassemia intermedia and hemoglobin E - $\beta$-thalassemia) to transfusion-dependent thalassemia (TDT) (thalassemia major). Treatment of TDT involves regular and lifelong blood transfusions leading to iron overload; long-term management of iron overload requires regular iron chelation therapy, ${ }^{9,10}$ However, iron chelation therapy is associated with significant toxicities and requires a high level of treatment adherence and monitoring that can be difficult to manage and may have a negative impact on patients' quality of life. ${ }^{11,12}$ Bone marrow transplantation offers potentially curative treatment,${ }^{13}$ but is not possible in all patients,,${ }^{14}$ and is associated with significant morbidity and mortality. ${ }^{15}$ Gene therapy has shown early promise but is still under investigation. ${ }^{16}$ The treatment of NTDT is based on managing the long-term complications of ineffective erythropoiesis, including chronic anemia and iron overload, ${ }^{17}$ using iron chelation therapy and occasional RBC transfusion..$^{18,19}$

Sotatercept is a ligand trap that inhibits transforming growth factor beta (TGF- $\beta$ ) superfamily members including growth differentiation factor 11 (GDF-11) and activin B. ${ }^{20,21}$ GDF-11 is overexpressed in immature erythroblasts in $\beta$-thalassemia. ${ }^{21}$ Aberrant GDF-11 production may induce expansion of erythroid progenitors and increase oxidative stress, leading to maturation arrest of late erythroid precursors and ineffective erythropoiesis. ${ }^{21}$ Preclinical work has shown that administration of an activin receptor IIA (ActRIIA) ligand trap decreases GDF11 concentration, reduces reactive oxidative stress levels, and promotes terminal maturation in immature erythroblasts. ${ }^{21}$ Sotatercept is a novel recombinant fusion protein consisting of the extracellular domain of the human ActRIIA (ACVR2A) linked to the human immunoglobulin G1 Fc domain. ${ }^{20}$ When administered subcutaneously, sotatercept increased hemoglobin levels and RBC count in healthy, postmenopausal women. ${ }^{22}$ In a phase II trial of patients with lower-risk myelodysplastic syndromes and anemia, sotatercept reduced transfusion burden in $47 \%$ of patients with a high transfusion burden, and increased hemoglobin levels in $58 \%$ of patients with a low transfusion burden..$^{23}$ In a $\beta$-thalassemia mouse model, RAP-011 (a murine analog of sotatercept) improved hematologic parameters including RBC count, total hemoglobin, hematocrit, and mean corpuscular volume. ${ }^{21}$

The aim of this phase II study was to determine a safe, tolerable, and effective dose of sotatercept to increase hemoglobin levels and reduce blood transfusion burden in adults with TDT and NTDT $\beta$-thalassemia.

\section{Methods}

In this phase II, open-label, dose-finding study, patients were enrolled at seven centers in France, Greece, Italy, and the United Kingdom (listed in the Online Supplementary Data) between November 2012 and November 2014. The study was approved by individual institutional review boards at participating centers and, where appropriate, national health authorities, and was conducted in compliance with the Declaration of Helsinki. All patients provided written informed consent. ClinicalTrials.gov registration number: NCT01571635.

\section{Inclusion criteria}

Eligible patients were aged $\geq 18$ years with a diagnosis of TDT or NTDT, and an Eastern Cooperative Oncology Group Performance Status of 0 to 1 . Transfusion dependence was defined as receiving $\geq 2 \mathrm{RBC}$ units every 30 days for $\geq 168$ days prior to study enrollment, with no transfusion-free period of $>45$ consecutive days during this period. The mean hemoglobin level before transfusion was $\leq 10.5 \mathrm{~g} / \mathrm{dL}$ in the 168 days prior to enrollment, with the last pretransfusion hemoglobin level preceding enrollment being $\leq 10.5 \mathrm{~g} / \mathrm{dL}$.

Non-transfusion dependence was defined as $\leq 1$ episode of transfusion during the 168 days prior to enrollment; an episode of transfusion was defined as $\leq 4 \mathrm{RBC}$ units received during the 168 days prior to enrollment. Exclusion criteria are listed in the Online Supplementary Data.

\section{Study design}

To determine a safe and tolerable dose of sotatercept, a doseescalation study was carried out. Patients were initially enrolled in two cohorts, receiving doses of $0.1 \mathrm{mg} / \mathrm{kg}$ and $0.3 \mathrm{mg} / \mathrm{kg}$, administered by subcutaneous injection every 3 weeks. Four dose-escalation cohorts, with doses of $0.5,0.75,1.0$, and $1.5 \mathrm{mg} / \mathrm{kg}$, were subsequently opened to enrollment. Details of the study design are included in the Online Supplementary Data.

\section{Study endpoints}

Primary efficacy endpoints were a reduction in transfusion burden of $\geq 20 \%$ from pretreatment levels, sustained for 24 weeks in TDT patients, and an increase in hemoglobin level of $\geq 1.0 \mathrm{~g} / \mathrm{dL}$ sustained for 12 weeks from mean pretreatment hemoglobin levels in NTDT patients. Hematologic parameters, including hemoglobin levels and RBC counts, were measured on days 1,8 , and $15( \pm 3$ days) of each 3 -week sotatercept dose period. Secondary endpoints included reduction in RBC transfusion burden in TDT patients, hemoglobin level increase from baseline in NTDT patients, and safety. Exploratory endpoints included iron metabolism markers (including serum ferritin and hepcidin), and clinical symptoms associated with ineffective erythropoiesis and anemia (including extramedullary hematopoiesis, leg ulcers, and bilirubin levels).

\section{Statistical analysis}

Efficacy analyses were carried out on the intent-to-treat population, which included all patients enrolled for treatment. Efficacy data are presented by assigned dose group. Safety analyses were conducted on the safety population, defined as those patients who received one or more dose of sotatercept. Safety data are presented prior to intrapatient dose escalation for sotatercept dose groups and presented post-intrapatient dose escalation for patients over- 
all. The data cutoff date for this analysis was November 27, 2015. Detailed statistical methods are included in the Online Supplementary Data.

\section{Results}

\section{Patients}

As of November 27, 2015, 46 patients had been enrolled between November 2012 and November 2014 - 16 with TDT and 30 with NTDT (Online Supplementary Figure S1). The patients' baseline demographic and disease characteristics are shown in Table 1; the data are presented by assigned dose level of sotatercept prior to dose escalation. All patients received two or more doses of sotatercept. The median duration of treatment was 19.6 months (range, 0.6-35.9) for NTDT patients and 13.8 months (range, 1.4-27.7) for TDT patients.

\section{Erythroid response}

Non-transfusion-dependent $\beta$-thalassemia patients

Of the 30 patients with NTDT treated with sotatercept doses of 0.1 to $1.0 \mathrm{mg} / \mathrm{kg}, 18(60 \%)$ achieved a mean hemoglobin increase of $\geq 1.0 \mathrm{~g} / \mathrm{dL}$, and 11 (37\%) had a mean hemoglobin increase of $\geq 1.5 \mathrm{~g} / \mathrm{dL}$ sustained for $\geq 12$ weeks (Figure 1A). The highest rate of response was seen with $0.75 \mathrm{mg} / \mathrm{kg}$ sotatercept: $86 \%$ (6 of 7 ) of the patients treated with this dose achieved an increase in hemoglobin of $\geq 1.5 \mathrm{~g} / \mathrm{dL}$. Responders receiving sotatercept $0.5 \mathrm{mg} / \mathrm{kg}$ experienced the greatest maximum increase in hemoglobin levels within 12 weeks versus baseline $(3.2 \pm 0.2 \mathrm{~g} / \mathrm{dL})$ (Figure 1B). No patients receiving sotatercept $0.1 \mathrm{mg} / \mathrm{kg}$ achieved a response.

The mean change in hemoglobin levels from baseline in NTDT patients is shown in Figure 2. No significant differences in reticulocyte count or fetal hemoglobin $(\mathrm{HbF})$ levels were reported for NTDT patients during the study (data not shown). The starting active dose of sotatercept in patients with NTDT, based on the observed responses, was $\geq 0.3 \mathrm{mg} / \mathrm{kg}$.

Of four patients with NTDT who were receiving concomitant hydroxyurea therapy at enrollment, three continued to receive hydroxyurea during the study (dose range $54-84 \mathrm{mg} / \mathrm{kg}$ ) without interruption or modification;

Table 1. Baseline characteristics of patients with non-transfusion-dependent and transfusion-dependent $\beta$-thalassemia treated with sotatercept by assigned dose level.

\begin{tabular}{|c|c|c|c|c|c|c|}
\hline \multirow[t]{2}{*}{ Characteristic } & \multirow[b]{2}{*}{$\begin{array}{c}0.1 \mathrm{mg} / \mathrm{kg} \\
(\mathrm{n}=8)\end{array}$} & \multicolumn{4}{|c|}{ Sotatercept dose } & \multirow[b]{2}{*}{$\begin{array}{l}\text { Overall } \\
(\mathrm{N}=46)\end{array}$} \\
\hline & & $\begin{array}{c}0.3 \mathrm{mg} / \mathrm{kg} \\
(\mathrm{n}=9)\end{array}$ & $\begin{array}{c}0.5 \mathrm{mg} / \mathrm{kg} \\
(\mathrm{n}=8)\end{array}$ & $\begin{array}{c}0.75 \mathrm{mg} / \mathrm{kg} \\
(n=12)\end{array}$ & $\begin{array}{c}1.0 \mathrm{mg} / \mathrm{kg} \\
(n=9)\end{array}$ & \\
\hline NTDT patients & $\mathrm{n}=6$ & $\mathrm{n}=6$ & $\mathrm{n}=6$ & $n=7$ & $\mathbf{n}=\mathbf{5}$ & $\mathrm{n}=\mathbf{3 0}$ \\
\hline $\begin{array}{l}\text { Age, years } \\
\text { Median } \\
\text { Range }\end{array}$ & $\begin{array}{c}39.5 \\
32.0-53.0\end{array}$ & $\begin{array}{c}47.0 \\
37.0-55.0\end{array}$ & $\begin{array}{c}39.0 \\
34.0-54.0\end{array}$ & $\begin{array}{c}43.0 \\
29.0-65.0\end{array}$ & $\begin{array}{c}41.0 \\
19.0-52.0\end{array}$ & $\begin{array}{c}42.0 \\
19.0-65.0\end{array}$ \\
\hline Female, n (\%) & $3(50)$ & $3(50)$ & $3(50)$ & $6(86)$ & $1(20)$ & $16(53)$ \\
\hline $\begin{array}{l}\text { Weight, kg } \\
\text { Median } \\
\text { Range }\end{array}$ & $\begin{array}{c}54.0 \\
48.0-85.0\end{array}$ & $\begin{array}{c}58.0 \\
53.6-65.0\end{array}$ & $\begin{array}{c}64.2 \\
41.0-75.0\end{array}$ & $\begin{array}{c}56.0 \\
47.6-75.0\end{array}$ & $\begin{array}{c}62.0 \\
56.0-67.0\end{array}$ & $\begin{array}{c}58.9 \\
41.0-85.0\end{array}$ \\
\hline $\begin{array}{l}\text { Hemoglobin, } \mathrm{g} / \mathrm{dL} \\
\text { Median } \\
\text { Range } \\
\text { Mean } \pm \text { SD }\end{array}$ & $\begin{array}{c}8.8 \\
5.9-10.7 \\
8.6 \pm 1.68\end{array}$ & $\begin{array}{c}8.5 \\
6.0-9.5 \\
8.3 \pm 1.26\end{array}$ & $\begin{array}{c}8.5 \\
6.4-9.3 \\
8.2 \pm 1.13\end{array}$ & $\begin{array}{c}8.7 \\
7.1-9.6 \\
8.5 \pm 0.89\end{array}$ & $\begin{array}{c}7.6 \\
6.6-9.4 \\
7.7 \pm 1.04\end{array}$ & $\begin{array}{c}8.4 \\
5.9-10.7 \\
8.3 \pm 1.18\end{array}$ \\
\hline $\begin{array}{l}\text { Mean corpuscular volume, fL } \\
\text { Mean } \\
\text { Median } \\
\text { Range }\end{array}$ & $\begin{array}{c}76.2 \\
75.8 \\
67.7-83.8\end{array}$ & $\begin{array}{c}75.6 \\
75.8 \\
61.6-90.5\end{array}$ & $\begin{aligned} & 75.5 \\
& 68.4 \\
& 62.6-103.4\end{aligned}$ & $\begin{array}{c}63.2 \\
61.1 \\
54.6-80.4\end{array}$ & $\begin{array}{c}78.6 \\
80.3 \\
70.6-89.3\end{array}$ & $\begin{array}{c}73.3 \\
72.1 \\
54.6-103.4\end{array}$ \\
\hline TDT patients & $\mathrm{n}=\mathbf{2}$ & $\mathrm{n}=3$ & $\mathrm{n}=2$ & $\mathrm{n}=\mathbf{5}$ & $\mathrm{n}=4$ & $\mathrm{n}=16$ \\
\hline $\begin{array}{l}\text { Age, years } \\
\text { Median } \\
\text { Range }\end{array}$ & $\begin{array}{c}41.5 \\
34.0-49.0\end{array}$ & $\begin{array}{c}34.0 \\
23.0-39.0\end{array}$ & $\begin{array}{c}35.0 \\
34.0-36.0\end{array}$ & $\begin{array}{c}45.0 \\
33.0-51.0\end{array}$ & $\begin{array}{c}39.5 \\
27.0-46.0\end{array}$ & $\begin{array}{c}35.5 \\
23.0-51.0\end{array}$ \\
\hline Female, n (\%) & $1(50)$ & $1(33)$ & $0(0)$ & $2(40)$ & $2(50)$ & $6(38)$ \\
\hline $\begin{array}{l}\text { Weight, kg } \\
\text { Median } \\
\text { Range } \\
\end{array}$ & $\begin{array}{c}49.4 \\
46.9-51.8 \\
\end{array}$ & $\begin{array}{c}65.7 \\
52.0-71.0 \\
\end{array}$ & $\begin{array}{c}70.7 \\
60.5-80.8 \\
\end{array}$ & $\begin{array}{c}58.0 \\
48.5-83.0 \\
\end{array}$ & $\begin{array}{c}63.0 \\
53.5-85.9 \\
\end{array}$ & $\begin{array}{c}60.1 \\
46.9-85.9 \\
\end{array}$ \\
\hline$\beta$-thalassemia major, n (\%) & $2(100)$ & $1(33)$ & $2(100)$ & $3(60)$ & $4(100)$ & $12(75)$ \\
\hline$\beta$-thalassemia intermedia*, $\mathrm{n}(\%)$ & 0 & $2(67)$ & 0 & $2(40)$ & 0 & $4(25)$ \\
\hline $\begin{array}{l}\text { Transfusion burden, } \\
\text { RBC units/24 weeks }\end{array}$ & 15,33 & $14,18,33$ & 30,30 & $8,18,18,30,35$ & $18,18,18,24$ & - \\
\hline $\begin{array}{l}\text { Hemoglobin, g/dL } \\
\text { Median } \\
\text { Range }\end{array}$ & $\begin{array}{c}9.5 \\
9.3-9.7\end{array}$ & $\begin{array}{c}8.6 \\
8.5-10.6\end{array}$ & $\begin{array}{c}9.8 \\
9.4-10.1\end{array}$ & $\begin{array}{c}8.9 \\
8.0-10.0\end{array}$ & $\begin{array}{c}9.6 \\
8.6-10.9\end{array}$ & $\begin{array}{c}9.3 \\
8.0-10.9\end{array}$ \\
\hline
\end{tabular}

NTDT: non-transfusion-dependent $\beta$-thalassemia;TDT: transfusion-dependent $\beta$-thalassemia; SD: standard deviation; RBC: red blood cell. *Patients with $\beta$-thalassemia intermedia gene mutations who met the transfusion burden requirement were classified as having TDT. $\uparrow$ Values presented for transfusion burden for individual TDT patients. 
two achieved a mean hemoglobin increase of $\geq 1 \mathrm{~g} / \mathrm{dL}$ sustained for $\geq 12$ weeks.

\section{Transfusion-dependent $\beta$-thalassemia patients}

Of 16 patients with TDT treated with sotatercept, ten $(63 \%)$ achieved a transfusion burden reduction of $\geq 20 \%$ sustained for $\geq 24$ weeks; seven patients (44\%) achieved a reduction of $\geq 33 \%$, and two patients $(13 \%$ ), a reduction of $\geq 50 \%$ (Figure 3 ). Five of the ten patients achieved transfusion burden reduction while maintaining stable or improved hemoglobin levels at 12 weeks. The mean change in hemoglobin level from baseline to the end of treatment was $0.7 \mathrm{~g} / \mathrm{dL}$ in all patients with TDT. Nine patients $(56 \%)$ achieved a reduction in transfusion frequency over 24 weeks, receiving fewer transfusions per 24 weeks during treatment, while maintaining stable or improved hemoglobin levels versus pretransfusion levels. Four patients $(25 \%)$ also achieved a reduction in transfusion frequency over 24 weeks; however, their hemoglobin levels were lower than pretransfusion levels. The remaining three $(19 \%)$ patients (2 receiving $0.75 \mathrm{mg} / \mathrm{kg}$ sotatercept, 1 receiving $0.3 \mathrm{mg} / \mathrm{kg}$ sotatercept) experienced an increase in transfusion frequency, requiring between 0.7 1.0 additional transfusions per 24 weeks, representing an increase of $6.7-17.2 \%$ from baseline. Based on the observed responses, the active starting dose of sotatercept in patients with TDT was $\geq 0.5 \mathrm{mg} / \mathrm{kg}$.

\section{Bilirubin}

For NTDT patients, indirect bilirubin and total bilirubin decreased by $5-25 \%$ for patients receiving $0.3,0.75$, and $1.0 \mathrm{mg} / \mathrm{kg}$ (Online Supplementary Figure S2A). Among TDT patients with available bilirubin data at baseline, indirect bilirubin and total bilirubin increased by between $15 \%$ and $80 \%$ during treatment versus baseline at all dose levels (Online Supplementary Figure S2B). However, the changes were not statistically significant, and there was wide variability in the level of change.
A

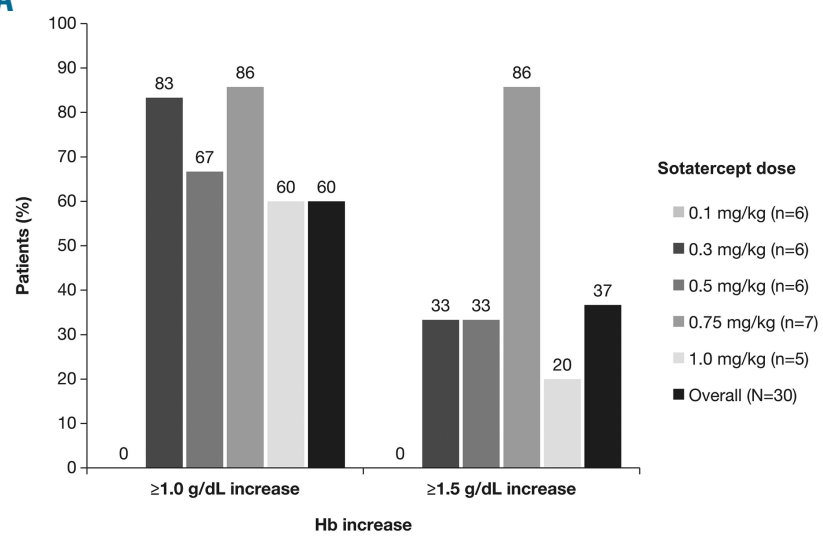

B

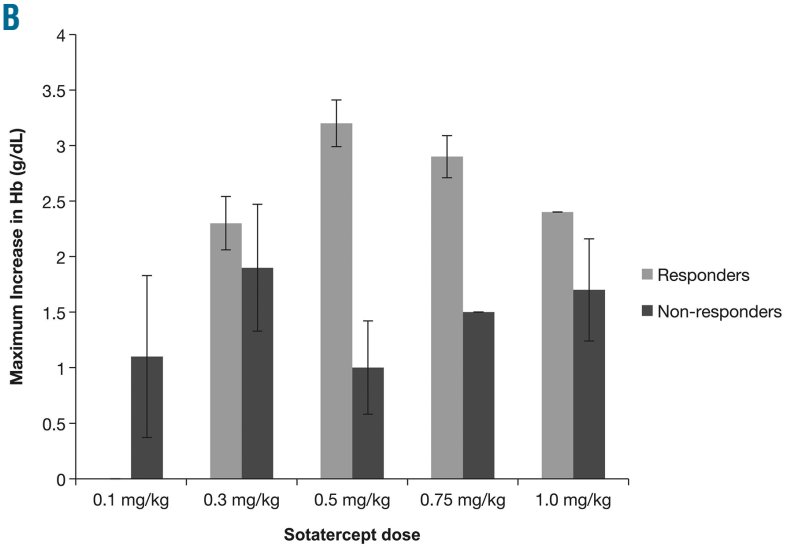

Figure 1. Response to sotatercept treatment in patients with non-transfusion-dependent $\beta$-thalassemia. (A) Percentage of sotatercept-treated non-transfusiondependent $\beta$-thalassemia patients achieving mean hemoglobin level increases from baseline of $\geq 1.0 \mathrm{~g} / \mathrm{dL}$ and $\geq 1.5 \mathrm{~g} / \mathrm{dL}$ sustained for $\geq 12$ weeks by assigned dose group. (B) Average maximum increase in hemoglobin levels within 12 weeks versus baseline levels in responders versus non-responders by dose group. Responders were those patients achieving $\mathrm{a} \geq 1.0 \mathrm{~g} / \mathrm{dL}$ increase in hemoglobin levels sustained for $\geq 12$ weeks. Error bars show the standard deviation of the mean. Hb: hemoglobin.

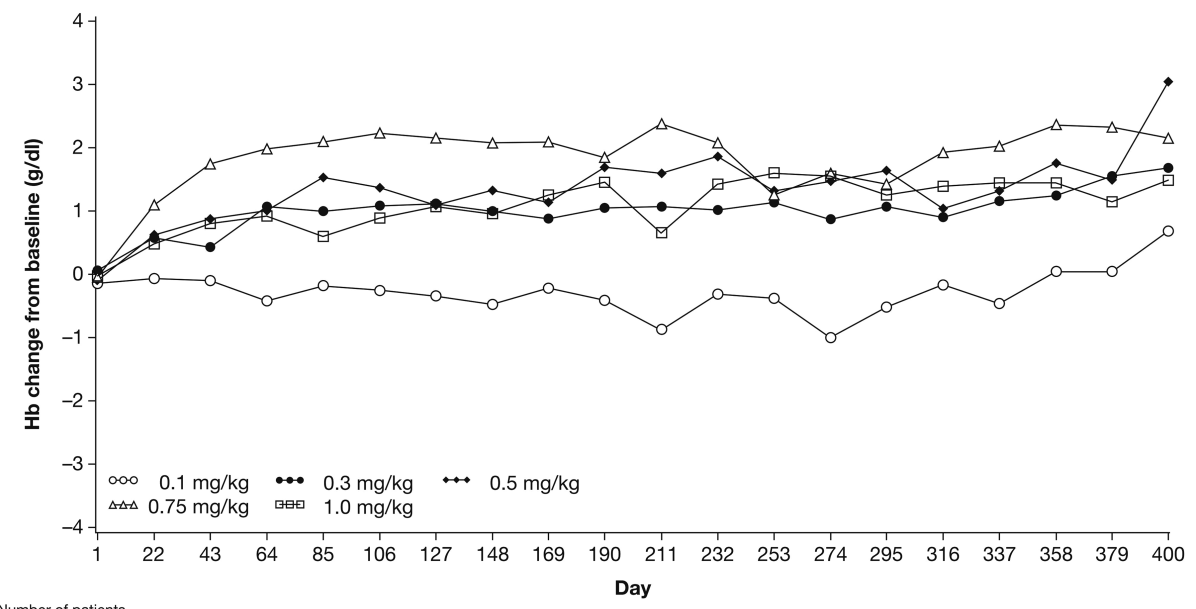

Figure 2. Mean change in hemoglobin levels from baseline up to day 400 in patients with non-transfusion-dependent $\beta$-thalassemia treated with different doses of sotatercept. Data are presented by assigned dose level, prior to intrapatient dose escalation. $\mathrm{Hb}$ : hemoglobin. 


\section{Clinical response \\ Extramedullary masses}

The effect of sotatercept on extramedullary masses, as measured by magnetic resonance imaging, was reported for four patients with NTDT and one with TDT. The TDT patient experienced a reduction in extramedullary mass volume at 12 months after treatment with sotatercept $0.75 \mathrm{mg} / \mathrm{kg}$ (data not shown); however, due to an unequal distribution of the mass, it was not possible to determine the exact volume of the mass. One NTDT patient experienced reduction in extramedullary mass volume at 12 months after treatment with sotatercept 0.3 $\mathrm{mg} / \mathrm{kg}$, with the reduction ranging from $0.4 \%$ to $59.3 \%$ across three separate extramedullary masses (Online Supplementary Figure S3A), alongside a stable increase in hemoglobin level. Another NTDT patient treated with sotatercept $1.0 \mathrm{mg} / \mathrm{kg}$ experienced volume increases of $67 \%$ and $55 \%$ in two extramedullary masses, at 7 months after treatment (Online Supplementary Figure S3B). This correlated with an increase in hemoglobin levels $(6 \mathrm{~g} / \mathrm{dL}$ at baseline versus $8 \mathrm{~g} / \mathrm{dL}$ at 7 months after treatment). Two NTDT patients experienced changes in volumes of extramedullary masses of between $-6.3 \%$ and $+22.5 \%$ at 11 months after treatment with sotatercept $1.0 \mathrm{mg} / \mathrm{kg}$ (data not shown).

\section{Leg ulcers}

Seven NTDT patients had a history of leg ulcers at baseline; the effect of sotatercept on chronic leg ulcers was reported for one NTDT patient. The chronic leg ulcers improved, and the dischromic area was reduced following treatment with sotatercept $0.5 \mathrm{mg} / \mathrm{kg}$ for 6 months (Online Supplementary Figure S4).

\section{Red blood cell morphology}

Changes to RBC morphology were recorded for all patients during the study. Representative images of the changes observed are provided in Online Supplementary Figure S5. Reductions in hypochromia, anisocytosis, and poikilocytosis, and the proportion of target cells were reported, and were associated with increased hemoglobin levels.

\section{Serum ferritin}

Among NTDT patients who responded to sotatercept treatment, mean levels of serum ferritin decreased regardless of iron chelation therapy status (Online Supplementary Figure $S 6 A, B)$. In contrast to NTDT patients, all TDT patients received iron chelation therapy. Levels of serum ferritin decreased over time in TDT patients (Online Supplementary Figure S6C).

\section{Safety}

Twenty-five of 46 patients (54\%) experienced one or more treatment-related adverse events; the most common treatment-related adverse events in all patients were bone pain $[26 \%(n=12)]$, arthralgia $[15 \%(n=7)]$, back pain $[11 \%$ $(\mathrm{n}=5)]$, asthenia/fatigue $[11 \%(\mathrm{n}=5)]$, and hypertension $[11 \%(n=5)]$ (Table 2). Treatment-related adverse events led to discontinuation of sotatercept in eight patients $(17 \%)$ (Table 2); of these eight patients, seven were not dependent on transfusions and one was transfusion-dependent.

All 46 patients experienced one or more treatment-emergent adverse events (Online Supplementary Table S1); six $(13 \%)$ experienced one or more serious adverse events (Online Supplementary Table S2). Nine patients (20\%) experienced one or more grade 3-4 treatment-emergent adverse

Table 2. Incidence of treatment-related adverse events of any grade occurring in sotatercept-treated patients in any dose cohort.

\begin{tabular}{|c|c|c|c|c|c|c|}
\hline \multirow[t]{2}{*}{ Adverse events, $\mathbf{n}(\%)$} & \multicolumn{5}{|c|}{$\begin{array}{l}\text { Sotatercept dose (data presented prior to } \\
\text { intrapatient dose escalation) }\end{array}$} & \multirow{2}{*}{$\begin{array}{c}\text { Overall (data presented } \\
\text { post-intrapatient dose } \\
\text { escalation) } \\
(\mathrm{N}=46)\end{array}$} \\
\hline & $\begin{array}{c}0.1 \mathrm{mg} / \mathrm{kg} \\
(\mathrm{n}=8)\end{array}$ & $\begin{array}{c}0.3 \mathrm{mg} / \mathrm{kg} \\
(\mathrm{n}=9)\end{array}$ & $\begin{array}{c}0.5 \mathrm{mg} / \mathrm{kg} \\
(\mathrm{n}=8)\end{array}$ & $\begin{array}{c}0.75 \mathrm{mg} / \mathrm{kg} \\
(n=12)\end{array}$ & $\begin{array}{c}1.0 \mathrm{mg} / \mathrm{kg} \\
(\mathrm{n}=9)\end{array}$ & \\
\hline Patients with $\geq 1$ treatment-emergent $\mathrm{AE}^{*}$ & $8(100)$ & $9(100)$ & $8(100)$ & $12(100)$ & $9(100)$ & $46(100)$ \\
\hline $\begin{array}{l}\text { Patients with } \geq 1 \text { treatment-related } \mathrm{AE}^{*} \\
\text { Bone pain } \\
\text { Arthralgia } \\
\text { Back pain } \\
\text { Asthenia/fatigue } \\
\text { Hypertension } \\
\text { Pain in extremity }\end{array}$ & $\begin{array}{l}2(25) \\
2(25) \\
0 \\
0 \\
0 \\
0 \\
0\end{array}$ & $\begin{array}{l}2(22) \\
2(22) \\
0 \\
0 \\
0 \\
0 \\
0\end{array}$ & $\begin{array}{l}4(50) \\
2(25) \\
1(13) \\
1(13) \\
1(13) \\
1(13) \\
1(13)\end{array}$ & $\begin{array}{l}8(67) \\
1(8) \\
3(25) \\
2(17) \\
3(25) \\
2(17) \\
2(17)\end{array}$ & $\begin{array}{l}6(67) \\
4(44) \\
1(11) \\
2(22) \\
1(11) \\
1(11) \\
0\end{array}$ & $\begin{array}{l}25(54) \\
12(26) \\
7(15) \\
5(11) \\
5(11) \\
5(11) \\
3(7)\end{array}$ \\
\hline $\begin{array}{l}\text { Patients with treatment-emergent } \\
\text { AE leading to discontinuation }{ }^{\dagger}\end{array}$ & $2(25)$ & 0 & $1(13)$ & $3(25)$ & $2(22)$ & $8(17)$ \\
\hline \multicolumn{7}{|l|}{$\begin{array}{l}\text { Treatment-emergent AE leading } \\
\text { to discontinuation }{ }^{\ddagger}\end{array}$} \\
\hline Hypertension & 0 & 0 & 0 & $2(17)$ & 0 & $2(4)$ \\
\hline Superficial thrombophlebitis & $1(13)$ & 0 & 0 & 0 & 0 & $1(2)$ \\
\hline Injection site erythema & 0 & 0 & 0 & $1(8)$ & 0 & $1(2)$ \\
\hline Pyrexia & 0 & 0 & 0 & 0 & $1(11)$ & $1(2)$ \\
\hline Extramedullary hematopoiesis & 0 & 0 & 0 & 0 & $1(11)$ & $1(2)$ \\
\hline Ventricular extrasystoles & 0 & 0 & $1(13)$ & 0 & 0 & $1(2)$ \\
\hline Hypersensitivity & 0 & 0 & 0 & $1(8)$ & 0 & $1(2)$ \\
\hline Bone pain & $1(13)$ & 0 & 0 & 0 & 0 & $1(2)$ \\
\hline
\end{tabular}

Adverse events (AE) in each dose cohort are presented prior to intrapatient dose escalation. Total $\mathrm{AE}$ are presented after-intrapatient dose escalation. ${ }^{*} \mathrm{AE}$ occurring in $\geq 5 \%$ of sotatercept-treated patients. $\mathrm{AE}$ occurring in any sotatercept-treated patient. ${ }^{\ddagger}$ One patient had both injection site erythema and hypersensitivity as $\mathrm{AE}$ leading to treatment discontinuation. 
events; hypertension and anemia were the most frequent $[4 \%(n=2)]$ (Online Supplementary Table S3). The incidences of anemia were not related to treatment with sotatercept and anemia resolved within one treatment cycle.

The most common treatment-emergent adverse events of any grade among the 30 NTDT patients were headache $[53 \%(\mathrm{n}=16)]$, arthralgia $[47 \%(\mathrm{n}=14)]$, cough $[40 \%$ $(\mathrm{n}=12)]$, and asthenia/fatigue $[37 \% \quad(\mathrm{n}=11)]$ (Online Supplementary Table S4).

The most common treatment-emergent adverse events among the 16 TDT patients were bone pain [63\% $(n=10)]$, back pain $(56 \%(n=9)]$, asthenia/fatigue $[56 \%(n=9)])$, headache $[44 \%(n=7)]$, and arthralgia [44\% ( $=7])$ (Online Supplementary Table S4). Most treatment-emergent adverse events were mild and did not lead to treatment discontinuation (Table 2).

Bone pain was reported equally among the different sotatercept dose cohorts; the mean time to first onset of bone pain was similar between dose cohorts and the duration of bone pain was short (mean 12.0 days).

Asthenia was less frequent at higher dose levels; $13 \%(3$ incidences/23 doses received) versus $5 \%$ (4 incidences/81 doses received) for TDT patients and $36 \%$ (47 incidences/132 doses received) versus $5 \%$ (3 incidences/67 doses received) for NTDT patients at $0.1 \mathrm{mg} / \mathrm{kg}$ and 1.0 $\mathrm{mg} / \mathrm{kg}$, respectively) (data not shown).

Observed differences between baseline and on-treatment laboratory values for liver and kidney function, including alanine aminotransferase, aspartate aminotransferase, and serum creatinine levels, were within the ranges expected for this population and were not related to treatment (data not shown).

Dose delays for safety reasons were reported in eight patients, all with NTDT.

\section{Discussion}

$\beta$-thalassemia is characterized by chronic anemia due to ineffective erythropoiesis and peripheral hemolysis. The current treatment for TDT is demanding, requiring regular blood transfusions and lifelong iron chelation therapy. No standardized treatment for NTDT is available, and no treatment is currently available to improve ineffective erythropoiesis. Previous investigational treatments for NTDT have included $\mathrm{HbF}$ modulators such as butyrates, azacitidine, or hydroxyurea, with or without erythropoietin; however, results with these and other modulators of $\mathrm{HbF}$ have been inconsistent. ${ }^{24,25}$

Sotatercept, a recombinant fusion protein that acts as a ligand trap for TGF- $\beta$ superfamily ligands, is hypothesized to improve late-stage erythropoiesis by reducing proliferation of early erythroid progenitors and precursors while increasing differentiation and maturation of late-stage RBC precursors. ${ }^{20,21}$ This drug may therefore present a novel approach to restoring effective erythropoiesis in $\beta$ thalassemia.

In this phase II, open-label, dose-finding study, sotatercept exhibited a good safety profile, and was tolerated by most patients. The most frequent adverse events were bone, articular or back pain, and asthenia/fatigue. Treatment discontinuation due to adverse events was rare, and the incidence of grade 3-4 adverse events was low. Changes in laboratory values for liver and kidney function were not thought to be treatment-related and were in line with fluctuations seen in $\beta$-thalassemia patients without treatment. The active dose of sotatercept was $\geq 0.3 \mathrm{mg} / \mathrm{kg}$ for NTDT patients and $\geq 0.5 \mathrm{mg} / \mathrm{kg}$ for TDT patients. Importantly, concomitant administration of hydroxyurea did not appear to interfere with the response to sotatercept, or with treatment compliance.

The majority $(75 \%)$ of NTDT patients treated with higher doses $(0.75-1.0 \mathrm{mg} / \mathrm{kg})$ of sotatercept achieved sustained increases in hemoglobin of $\geq 1.0 \mathrm{~g} / \mathrm{dL}$. Similarly, $66 \%$ of TDT patients treated with higher doses of sotatercept $(0.75-1.0 \mathrm{mg} / \mathrm{kg})$ achieved reductions of $\geq 33 \%$ in $\mathrm{RBC}$ transfusion requirements. The increase in hemoglobin and reduction in $\mathrm{RBC}$ transfusion correlated with increased serum exposure to sotatercept (data not shown), although responses were not proportional to sotatercept dose because of interpatient variability in serum drug exposure. The small number of patients in each dose group makes comparisons between sotatercept levels difficult. Studies are ongoing to identify any differences in baseline characteristics between responders and nonresponders.
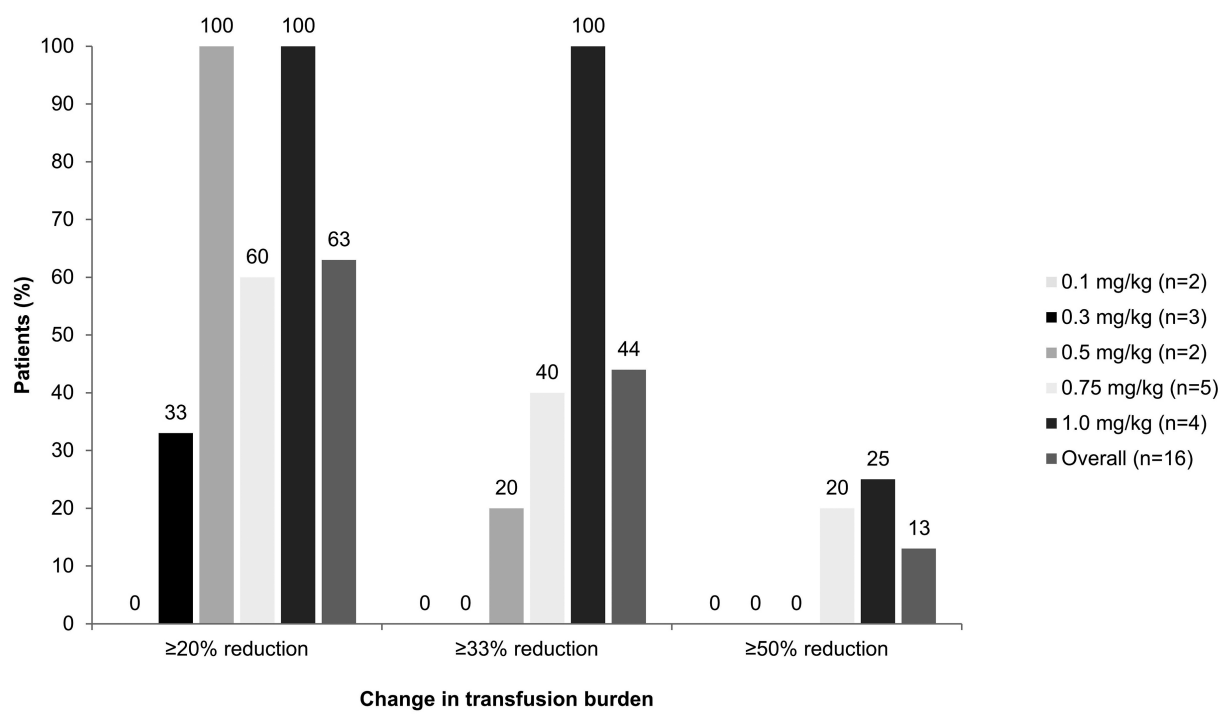
Ineffective erythropoiesis in $\beta$-thalassemia is associated with increased iron absorption, and patients with TDT often require regular $\mathrm{RBC}$ transfusions, further increasing the risk of iron overload. Reducing ineffective erythropoiesis and transfusion burden will decrease the rate of iron loading and associated complications such as heart, liver, and endocrine disorders. In this study, decreases in serum ferritin levels were observed in sotatercept-treated patients with NTDT and TDT, with the decreases occurring in a dose-dependent manner, regardless of concurrent treatment with iron chelation therapy. Although these results suggest that sotatercept may reduce iron absorption by reducing ineffective erythropoiesis, other mechanisms such as removal or redistribution of iron from overloaded organs may also contribute to reduced iron levels. Further studies will be required to elucidate the mechanism of action; however, a reduction in iron overload with long-term use may translate into improved outcomes for patients.

Sotatercept treatment was associated with a reduction in the volume of extramedullary masses, as measured by magnetic resonance imaging, in two patients with recorded data - one with NTDT and one with TDT. However, this change in extramedullary mass volume was not observed for all patients, and, due to technical difficulties, precise estimation of extramedullary mass volume was not always possible. Reductions in the volumes of these masses did not appear to correlate with response. Further study is needed to determine the effect of sotatercept on extramedullary masses.

In rodent models, sotatercept acts on ineffective erythropoiesis to reduce production of $\alpha$-globin aggregates and apoptosis of late erythroid precursors, thereby increasing the efficiency of RBC production and hemoglobin levels. ${ }^{21,26}$ Although hemoglobin levels increased in NTDT patients during the study, no significant differences in $\mathrm{HbF}$ or reticulocyte count were reported. In a small subset of patients, normalization of RBC morphology was reported and associated with increasing hemoglobin levels over time. These data suggest that sotatercept may increase the lifespan of RBC in part by improving reticulocyte quality. These changes are consistent with the mode of action of sotatercept as a ligand trap for TGF- $\beta$ superfamily members, including GDF- 11 . Binding of sotatercept to GDF-11 inhibits SMAD2/3 signaling, reducing TGF- $\beta$ superfamily ligand signaling and thereby promoting terminal differentiation of erythroblasts. ${ }^{20}$

There are some limitations to this study, notably the small number of patients enrolled, which limited the abil- ity to draw comparisons between different sotatercept dose groups. The inclusion of both NTDT and TDT $\beta$ thalassemia patients also resulted in patients being grouped into smaller subgroups that further limited the scope of the study, especially as intrapatient dose escalation was allowed. The short duration of follow-up may be another limitation, and longer follow-up would provide information on the long-term clinical efficacy and safety of sotatercept.

This study demonstrated the safety and efficacy of sotatercept in patients with $\beta$-thalassemia. An improvement in hemoglobin levels and reduction in transfusion burden with sotatercept treatment have also been demonstrated in a phase II study of anemia patients with lower-risk myelodysplastic syndromes. ${ }^{23}$ This suggests that sotatercept may work to decrease ineffective erythropoiesis in multiple disease states via a single underlying mode of action. Preliminary data with sotatercept led to the initiation of a similar phase II study in $\beta$-thalassemia of the related recombinant fusion protein, luspatercept. Luspatercept has more selective activity on GDF11 , and is also safe and effective in the treatment of $\beta$-thalassemia (Piga A, et al. manuscript submitted) and myelodysplastic syndromes. ${ }^{27}$ Luspatercept comprises the modified extracellular domain of human ActRIIB linked to the human IgG Fc domain, ${ }^{26,28}$ and has a similar mode of action to sotatercept but does not bind to other members of the TGF- $\beta$ superfamily, such as activin $A^{20,26} \mathrm{~A}$ double-blind, randomized, placebo-controlled phase III trial of luspatercept in patients who require regular RBC transfusions due to $\beta$-thalassemia has recently completed recruitment (BELIEVE; NCT02604433). Luspatercept is also being studied in a phase III trial of patients with very low-, low- and intermediate-risk myelodysplastic syndromes (MEDALIST; NCT02631070). While the decision was made not to advance trials of sotatercept in $\beta$-thalassemia due to binding of sotatercept to activin A, sotatercept represents the first drug developed in its class, functioning as a TGF- $\beta$ superfamily inhibitor to correct ineffective erythropoiesis. TGF- $\beta$ superfamily inhibition may provide an alternative or complementary treatment option for patients with $\beta$-thalassemia.

\section{Acknowledgments}

The authors would like to thank all the patients and their families who participated in this study. The authors received editorial and writing support from Victoria Edwards, PhD, from Excerpta Medica, funded by Celgene Corporation. Celgene Corporation and Acceleron Pharma provided funding for this study.

\section{References}

1. Galanello R, Origa R. Beta-thalassemia. Orphanet J Rare Dis. 2010;5:11.

2. Malamos B, Belcher EH, Gyftaki E, Binopoulos D. Simultaneous studies with Fe59 and Cr51 in congenital haemolytic anaemias. Nucl Med (Stuttg). 1961;2:1-20.

3. Weatherall DJ, Clegg JB. The Thalassemia Syndromes. 2nd ed. Oxford, England: Blackwell Scientific Publications; 1972

4. Arlet JB, Dussiot M, Moura IC, Hermine O,
Courtois G. Novel players in $\beta$-thalassemia dyserythropoiesis and new therapeutic strategies. Curr Opin Hematol. 2016;23(3) 181-188.

5. Rund D, Rachmilewitz E. Beta-thalassemia. N Engl J Med. 2005;353(11):1135-1146.

6. Melchiori L, Gardenghi S, Rivella S. Betathalassemia: HiJAKing ineffective erythropoiesis and iron overload. Adv Hematol, 2010;2010:938640.

7. Fibach E, Rachmilewitz EA. Does erythropoietin have a role in the treatment of $\beta$ - hemoglobinopathies? Hematol Oncol Clin North Am. 2014;28(2):249-263.

8. Gardenghi S, Grady RW, Rivella S. Anemia, ineffective erythropoiesis, and hepcidin: interacting factors in abnormal iron metabolism leading to iron overload in $\beta$-thalassemia. Hematol Oncol Clin North Am. 2010;24(6):1089-1107.

9. Cappellini MD, Cohen A, Porter J, Taher A, Viprakasit V. Guidelines for the Management of TD Thalassemia (TDT). 3rd ed Nicosia, Cyprus: Thalassemia International 
Federation; 2014

10. Rund D. Thalassemia 2016: modern medicine battles an ancient disease. Am J Hematol. 2016;91(1):15-21.

11. Haghpanah S, Nasirabadi S, Ghaffarpasand $F$, et al. Quality of life among Iranian patients with beta-thalassemia major using the SF-36 questionnaire. Sao Paulo Med J. 2013;131(3):166-172.

12. Dahlui M, Hishamshah MI, Rahman AJ, Aljunid SM. Quality of life in transfusiondependent thalassemia patients on desferrioxamine treatment. Singapore Med J. 2009;50(8):794-799.

13. Baronciani D, Angelucci E, Potschger U, et al. Hematopoietic stem cell transplantation in thalassemia: a report from the European Society for Blood and Bone Marrow Transplantation Hemoglobinopathy Registry, 2000-2010. Bone Marrow Transplant. 2016;51(4):536-541.

14. Qari $\mathrm{MH}$, Wali $\mathrm{Y}$, Albagshi $\mathrm{MH}$, et al. Regional consensus opinion for the management of beta thalassemia major in the Arabian Gulf area. Orphanet J Rare Dis. 2013;8:143.

15. Angelucci E, Matthes-Martin S, Baronciani D, et al. Hematopoietic stem cell transplantation in thalassemia major and sickle cell disease: indications and management recommendations from an international expert panel. Haematologica. 2014;99(5): 811-820.
16. Negre O, Eggimann AV, Beuzard Y, et al Gene therapy of the $\beta$-hemoglobinopathies by lentiviral transfer of the $\beta(A(T 87 \mathrm{Q})$ )-globin gene. Hum Gene Ther. 2016;27(2):148165.

17. Saliba AN, Taher AT. Morbidities in nontransfusion-dependent thalassemia. Ann N Y Acad Sci. 2016;1368(1):82-94.

18. Taher A, Vichinsky E, Musallam K, Cappellini MD, Viprakasit V. Blood transfusion. In: Weatherall D, ed. Guidelines for the Management of Non Transfusion Dependent Thalassaemia (NTDT). Nicosia, Cyprus: Thalassaemia International $\mathrm{Fe}$ deration; 2013.

19. Rachmilewitz EA, Giardina PJ. How I treat thalassemia. Blood. 2011;118(13):34793488.

20. Carrancio S, Markovics J, Wong P, et al. An activin receptor IIA ligand trap promotes erythropoiesis resulting in a rapid induction of red blood cells and haemoglobin. Br J Haematol. 2014;165(6):870-882.

21. Dussiot M, Maciel TT, Fricot A, et al. An activin receptor IIA ligand trap corrects ineffective erythropoiesis in $\beta$-thalassemia. Nat Med. 2014;20(4):398-407.

22. Ruckle J, Jacobs M, Kramer W, et al. Singledose, randomized, double-blind, placebocontrolled study of ACE-011 (ActRIIA IgG1) in postmenopausal women. J Bone Miner Res. 2009;24(4):744-752.
23. Komrokji R, Garcia-Manero G, Ades L, et al. Sotatercept with long-term extension for the treatment of anemia in patients with lower-risk myelodysplastic syndromes: a phase 2, dose-ranging trial. Lancet Haematol. 2018;5(2):e63-e72.

24. Porter J, Garbowski M. Novel erythropoiesis stimulating agents in thalassemia. European Hematology Association Education Programme. 2015:9:311-320

25. Taher AT, Musallam KM, Karimi M, et al. Overview on practices in thalassemia intermedia management aiming for lowering complication rates across a region of endemicity: the OPTIMAL CARE study. Blood. 2010;115(10):1886-1892.

26. Suragani RN, Cadena SM, Cawley SM, et al. Transforming growth factor- $\beta$ superfamily ligand trap ACE-536 corrects anemia by promoting late-stage erythropoiesis. Nat Med. 2014;20(4):408-414.

27. Platzbecker U, Germing U, Götze KS, et al Luspatercept for the treatment of anaemia in patients with lower-risk myelodysplastic syndromes (PACE-MDS): a multicentre, open-label, phase 2 dose-finding study with long-term extension study. Lancet Oncol. 2017;18(10):1338-1347.

28. Attie KM, Allison MJ, McClure T, et al. A phase 1 study of ACE-536, a regulator of erythroid differentiation, in healthy volunteers. Am J Hematol. 2014;89(7):766-770. 